Article

\title{
Evaluation of Household Food Waste Generation in Hanoi and Policy Implications towards SDGs Target 12.3
}

\author{
Chen Liu ${ }^{1, *}$ and Trung Thang Nguyen ${ }^{2}$ \\ 1 Institute for Global Environmental Strategies (IGES), 2108-11 Kamiyamaguchi, Hayama, \\ Kanagawa 240-0115, Japan \\ 2 Institute of Strategy and Policy on Natural Resources and Environment (ISPONRE), \\ 479 Hoang Quoc Viet str., Bac Tu Liem dist., Hanoi 100000, Vietnam; ntthang@isponre.gov.vn \\ * Correspondence: c-liu@iges.or.jp
}

Received: 14 July 2020; Accepted: 10 August 2020; Published: 13 August 2020

\begin{abstract}
The issue of food waste, especially in developing economies, is a puzzle. Hanoi was selected as a case study to examine the current situation of food waste generated by consumers through daily habits/practices and to evaluate options for preventing and reducing food waste at the policy level through a literature/policy review and interview-style survey. An analysis of responses found that the self-reported food waste generation rate in Hanoi averaged $1192 \mathrm{~g} /$ day/household in urban areas and $1694 \mathrm{~g} /$ day/household in rural areas; cooking waste generated during meal processing/preparation accounts for more than $70 \%$ of the total; less than $20 \%$ of respondents separated out kitchen waste for reuse/recycling before disposal; expiration dates and deteriorating quality were cited as primary reasons for food waste at home in contrast with larger portions and over-ordering outside the home; leftover food is used indirectly as animal feed in urban areas and directly in rural areas; and most respondents indicate a willingness to reduce, reuse, and recycle food waste. To achieve SDG target 12.3, policymakers and practitioners must develop comprehensive food waste policies and actions targeting the entire supply chain, implement practical food waste management systems, and promote sufficiency strategies for saving food, reducing food waste, and maintaining health and well-being.
\end{abstract}

Keywords: food waste; lifestyle; SDGs; households; Hanoi

\section{Introduction}

A third of all food produced worldwide for human consumption is lost along the food management chain [1]. This lost food is a source of enormous waste in the form of valuable resources, and also contributes to the degradation of the environment [2], as well as adding to the increasing volume of greenhouse gas (GHG) emissions [3] and skyrocketing social and economic costs [4]. Moreover, the generation of food waste is also a moral issue when considering that there are 795 million undernourished people around the world [5]. In light of this, over the course of implementing the Paris Agreement and the UN's 2030 Sustainable Development Goals (SDGs), policymakers, practitioners, and academics have increasingly acknowledged the urgency of addressing the issue of food waste. The SDGs adopted by the United Nations Member States set a target to "by 2030, halve per capita global food waste at the retail and consumer levels and reduce food losses along production and supply chains, including post-harvest losses" [6]. To achieve this target, policies must encourage widespread adoption of certain practices along the food supply chain [7].

Food loss and waste occur at all stages of the food supply chain in different countries for a variety of reasons and can vary by culture [3]. There is no universally-agreed upon definition for food loss and waste [8,9], which has resulted in the publication of inconsistent data on food loss and waste in existing 
literature. To ensure that the results from this study are comparable to data in other studies, this paper defines "food waste" as "any food, and inedible parts of food, removed from the food supply chain to be recovered or disposed," as proposed by FUSIONS [9]. The term "food loss" in this paper is used to describe a reduction in edible food at the beginning of the supply chain, while "food waste" refers to losses that occur at the end of the supply value chain, or consumption stage, as proposed by FAO in 2011 [8].

Research on food loss and waste began in the late 1980s, and since 2005, data on this issue has become more widely available [10]. However, there is little data to be found in the food waste research landscape in Asia [11], and there is even less literature on food waste in the consumption phase (see 2.1 below). It is generally recognised that on the global level, the consumption phase in developed countries is the largest single contributor to the rising generation of food waste, whereas larger food losses occur during the production and post-harvest phases in developing countries [4]. However, it has been argued that the boundary of consumption habits between developing and developed countries is more blurred in urban settings, meaning that food waste during the consumption phase in developing countries may be as extensive as in developed countries. For example, the volume of food waste generated in Bangkok is even higher than the average in many developed cities and countries [12]. Factors such as the rapidly growing urban middle class [13] and increased income [14], greater spending power [15], dietary transitions towards westernised consumption patterns [16], modern retail diffusion [17], and time scarcity [18] impact the generation of food waste in rapidly urbanising localities. Where developed countries have created adequate policies and systems to manage waste, developing countries have not yet reached this stage; even when waste management and $3 R$ policies are in place, developing countries may falter over implementation. Research analysing food waste in the consumption phase in developing countries has remained static at the preliminary stage and little is known about the determinants of consumer food waste and the underlying factors that encourage, drive, or impede food waste prevention behaviours. It is especially urgent to promote food waste studies to link waste to its producers and examine food waste reduction policy implications in the cities of developing countries where the amount of food waste is dramatically increasing, but where both existing data and the capacity to tackle this issue are limited.

Today, Vietnam is one of the most dynamic emerging economies in the East Asia region, with substantial population growth (jumping from 61.1 million in 1986 to 94.7 million in 2018 and forecast to rise to 120 million by 2050), accelerated economic growth (GDP per capita more than doubled by 2.7 times between 2002 and 2018, reaching 7\% GDP growth since 2018), rapid urbanisation (rising from $29 \%$ in 2008 to $38.4 \%$ in 2018), a swiftly emerging urban middle class (rising from $7.7 \%$ in 2014 to $13.3 \%$ in 2016) and fast-growing development of consumer goods and services, as well as tourism (total tourism revenue increased more than three times from 200 trillion VND (Vietnamese Dong) in 2013 to 637 trillion VND in 2018) in recent years [19-22]. These developments will lead to the consumption of more food and other goods, causing food waste generation rates to skyrocket. With farmland making up 34.7\% of the total land area and the agriculture, forestry, and fishing sector accounting for $37.7 \%$ of total employment in the country, Vietnam faces challenges with food loss and food waste along the entire food supply chain in both production and consumption.

Hanoi, the capital of Vietnam, is one of the most vibrant cities in the Asia and Pacific region with relatively high economic growth that is expected to continue rising rapidly in the coming years. The city is facing a number of challenges in solid waste management as it sees an increase in the generation of solid waste in terms of quantity, type, and toxicity. The city produces 8629 tonnes of domestic solid waste per day $(3,149,723$ tonnes/year), and the average amount of municipal solid waste (MSW) generated daily per capita is $1.1 \mathrm{~kg}$ [23]. This waste is discharged from municipal sources, including households, restaurants, markets, and businesses. The rate of waste generated in Hanoi averagely increases by $5 \%$ each year due to the growing population and rising economy [23]. The quantity and quality of MSW generated in Hanoi have changed dramatically due to the large concentrated population and the effects of lifestyle changes as a result of economic development $[24,25]$. 
It is estimated that by 2030, this figure will have reached $1.72 \mathrm{~kg} /$ person/day [23]. If considering food waste as the organic fraction of MSW, food waste accounted for $53.81 \%$ of MSW in 2012 (excluding paper residue), and with a growing population, it is estimated that the volume of domestic solid waste in Hanoi, including food waste, will continue to increase. Meanwhile, more than $80 \%$ of MSW is landfilled, which contributes to rising greenhouse gas emissions (GHGs). The city faces a series of challenges related to economic growth, environmental protection, and sustainability in agriculture and food systems, including food security, food safety, and food waste, as well as waste management and improving the quality of life.

In this paper, we selected the city of Hanoi as a case study to examine the current situation of food waste generated by consumers through daily habits and practices, and evaluated options for preventing and reducing food waste at the policy level. For this purpose, we

(1) review relevant food waste policies, strategies, and plans through a literature/policy review, and provide insights into policy implications to address issues, and

(2) conduct a questionnaire survey that includes a range of questions on the daily food-related practices of respondents at the household level, including eating habits (eating out, consuming ready-made food at home, and eating in), waste disposal practices, and other relevant points. This glimpse into daily practices is expected to provide an insight into the ways in which consumers generate food waste.

\section{Policy/Literature Review}

\subsection{Household Food Waste Studies in Asian Developing Countries}

The number of studies on consumer-generated food waste has grown since private households were identified as key actors in food waste generation in developed economies. Aschemann-Witzel et al. [26] published a study on factors behind the generation of food waste by consumers in households and along supply chains, demonstrating that motivation to avoid food waste, management skills in providing and handling food, and trade-offs between priorities have an extensive influence on the food waste behaviour of consumers. Roodhuyzen et al. [27] developed a framework that conceptualised the generation of consumer food waste in relation to stages of the household supply chain and identified and categorised potential factors of consumer food waste as behavioural, personal, product, and societal factors. Schanes et al. [28] systematically reviewed the rising number of empirical studies on consumer food waste practices and the factors that foster and impede the generation of food waste at the household level. This study reveals food waste to be a complex and multi-faceted issue that cannot be attributed to a single variable. Given the complex nature of food waste, a growing body of literature sheds light on food-related practices and routines, ranging from planning and shopping, to storing, cooking, eating, and managing leftovers, within the context of food waste generation by adopting practice theories and other conceptual approaches [28]. Due to the increased level of interest in research on the topic of food waste over the past decade, academic studies dedicated to this topic have emerged in Asian developing economies. For example, a material flow analysis among middle-class households in Bengalaru, India was combined with a social practice approach to understand how and in what way food is wasted in the post-consumption stage [29]. Taste preference has also been examined in the context of food provision and wastage in Bengaluru and Metro Manila [30]. Soma explores the transformation of household food consumption and food waste practices with the rise of supermarkets [31,32]. In yet another example, Liu et al. [12] analysed a case study on Bangkok using a questionnaire similar to the one in this study to examine the ways in which food waste is generated by consumers. Although Asia offers rich socio-economic dimensions and cultures where food waste issues can be examined from a number of different angles, this study has been limited in scope to present readers with an opportunity to gain a deeper understanding of food waste and to improve the governance of food waste, especially in Asian developing economies. 


\subsection{Relevant Policies, Strategies and Initiatives on the Issue of Food Waste at the National and Local Government Level}

A review of documentation on food, food security, waste management, and 3R (reduce, reuse, recycle) policies, as well as on related food loss and food waste issues, was conducted to consider food waste solutions along the entire supply chain. The overall structure of waste management policies in Vietnam, along with related food loss and food waste policies is summarised in Figure 1. This structure shows that (1) Vietnam has no specific laws, policies, and strategies addressing the issue of food waste, and (2) there are two separate dimensions to food loss and food waste: the first is a policy on reducing post-harvest loss (generated during handling, storage, processing, distribution, and at the market), and the second is a policy on food waste managed as regular municipal solid waste. At the policy level, food waste is considered to be similar to organic waste in that source segregation, waste reduction, and community composting or integrated waste treatment facilities at disposal sites are embedded in MSW plans. The primary guidance on this topic is incorporated into the following policies and strategic plans.

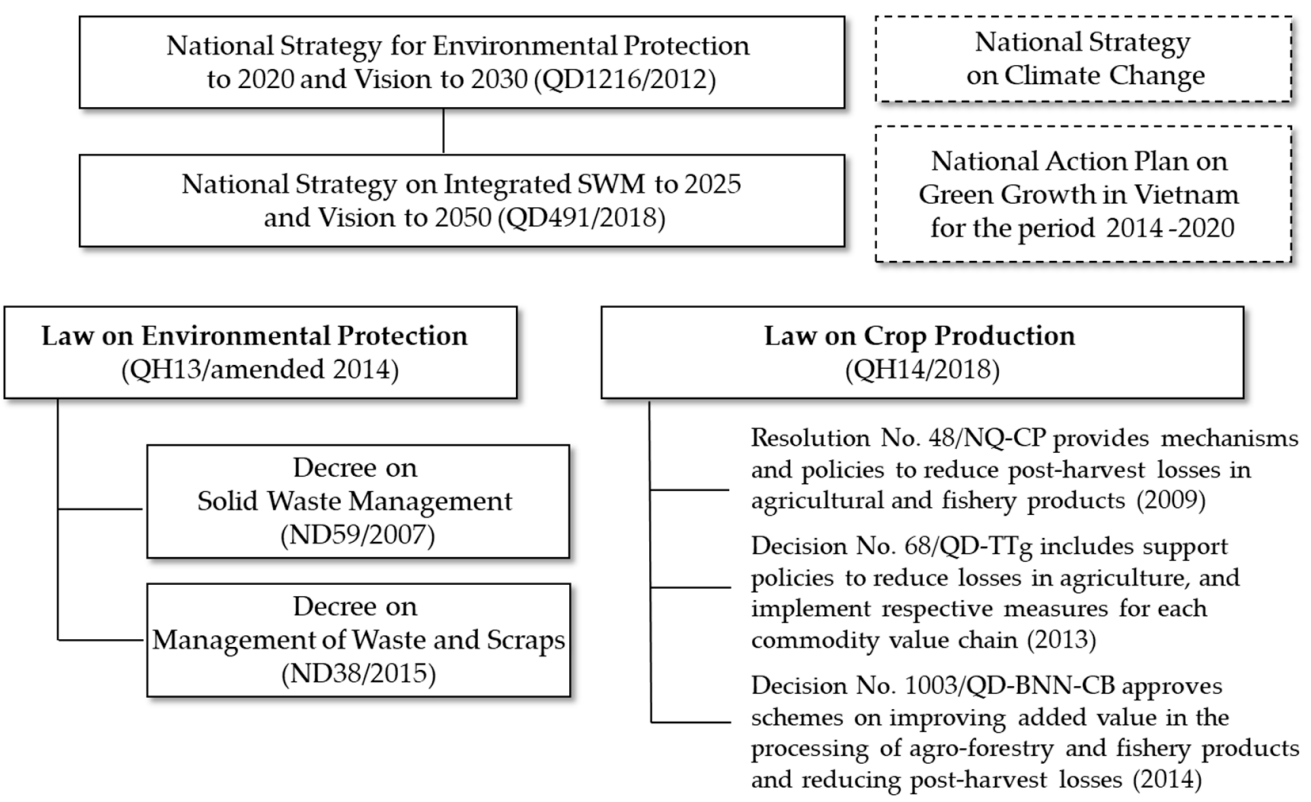

Figure 1. Overall structure of food loss and food waste-related policies in Vietnam.

In order to reduce post-harvest losses and facilitate the transformation and restructuring of agriculture, a number of policies have been put into place, including Resolution No. 48/NQ-CP in 2009 (providing mechanisms and policies to reduce post-harvest losses in agricultural and fishery products (2009)), Decision No. 68/2013/QD-TTg on 14 November 2013 by the Prime Minister on support policies to reduce losses in agriculture, and Decision No. 1003/QD-BNN-CB on 14 May 2014 by the Ministry of Agriculture and Rural Development (MARD) approving schemes to increase value-add in processed agricultural, forestry, and fishery products and setting 2020 as the target year for reducing post-harvest losses. In 2018, the Law on Crop Production (Law No. 31/2018/QH14) was issued with regulations on harvest activities to limit food loss and ensure quality and cost efficiency. The government has also introduced a number of policies to attract the private sector, including investments in technological innovation, increasing the rate of intensive processing products, ensuring food safety, setting competitive prices, and meeting market requirements, as well as investments in advanced technologies to produce high value-add products from agricultural waste.

Vietnam has a relatively comprehensive legal framework on solid waste already in place under the Law on Environmental Protection. This Law was first issued in 1993 and revised in 2005 and 2014, and contains a separate chapter on waste management (Chapter IX). Article 95 of this Law stipulates that waste generators have a "responsibility to classify ordinary solid waste at source to facilitate reuse, 
recycling, energy recovery, and processing." This was further clarified in Decree No. 38/2015/ND-CP on waste management and scraps issued on 24 April 2015 which expands on policies on waste prevention, reuse, recycling, energy recovery, and disposal. The Decree also mentions separation at source and fees in relation to household waste and contains a section on technology for the disposal of household waste that specifies the use of organic fertilisers.

Following this approach, Decision No. 491/QD-TTg was issued on 7 May 2018 approving revisions to the National Strategy on Integrated Solid Waste Management (SWM) to 2025, with a vision to 2050. The revised strategy addresses the high rate of food and organic waste in domestic waste and encourages environmentally friendly recycling, reuse, and disposal solutions. A number of targets to 2025 have been set up including (i) collecting and treating $90 \%$ of the total domestic solid waste generated in urban areas; (ii) enhancing the capability to reuse and recycle; (iii) striving to achieve a rate of less than $30 \%$ of collected domestic solid waste directly transported to landfill; (iv) collecting, storing, transporting, and treating $80 \%$ of domestic solid waste generated in concentrated rural residential areas on-site or through centralised treatment systems to meet environmental protection requirements and; (v) reusing, recycling, composting, or self-treating organic waste in households in rural areas to produce compost for local use.

To date, food waste has not been specifically mentioned in the Law on Environmental Protection, and waste management as a whole is referred to from the perspective of prevention through reuse, recycling, waste-to-energy, and disposal. The Law specifies the responsibilities of households in minimising and separating waste and partially covering costs for waste collection. The Law, which addresses the management of food waste generated by households, is currently under revision; the bill has been submitted to the National Assembly for debate and is slated for adoption in November 2020. Specifically, the draft Law specifies that household waste should be separated into (i) recyclables; (ii) food waste and organic waste; (iii) hazardous waste; (iv) bulky waste; and (v) other waste. The draft Law also states that collection and transportation fees for food waste should be lower than other household waste and that provincial and municipal authorities shall regulate waste management in households and set applicable fees. However, the draft Law does not mention the management of food loss in crop harvesting and post-harvest, logistics/distribution processes, or in restaurants (MONRE, 2020. Draft version of Law on Environmental Protection, which was submitted to the National Assembly on 23 March 2020).

In addition, the Law on Food Safety, issued in 2010 and revised in 2018, which acts as the guiding principle for food safety related incidents, states that "food should not cause harm to people's health and lives." This Law specifies requirements on hygienic levels at commercial sites and prohibits the use of expired materials and additives in food preparation, both of which could have a trade-off effect on food saving and food waste reducing.

On the ground, there are also a number of initiatives and good practices by local governments, the private sector, NPOs/NGOs, civil society, and other stakeholders on reducing food waste. For example, volunteer-based Hanoi Food Rescue was established in 2013 with sponsorship from REACH, a non-profit organisation operating in the field of training and job support for students in Vietnam who find themselves in difficult circumstances. Tet Donation is an annual event organised to collect quality leftover food after the Lunar New Year for the poor and homeless. Furthermore, many private enterprises have also invested in the processing and recycling of food waste and organic waste, such as the Vietnam Food Joint Stock Company (VNF), which has produced animal feed from shrimp shell by-products using enzymatic hydrolysis technology.

\section{Methodology of Household Survey}

\subsection{Content of the Questionnaire}

In order to clarify the impact of consumer behaviour on food waste generation and intentions to reduce food waste, a questionnaire survey was conducted in both urban and rural areas of Hanoi 
between 15 January and 28 February 2019 in collaboration with the Department of Environment and Sustainable Development under the Institute of Strategy and Policy on Natural Resources and Environment (ISPONRE) in Vietnam.

The questionnaire survey (see Supplementary Materials) for consumers on food waste mainly consisted of four sections and covered a range of daily activities. The first part included basic information about the respondents, such as sex, age, occupation, educational level, and household income. The second section asked respondents to self-report on daily food waste generation in their households, which included cooking waste and leftovers. The third part posed questions about the respondents' daily food related practices, such as their eating, shopping, cooking, and food management habits. The fourth section focussed on respondents' waste separation habits and food waste disposal in households, and the last part contained questions about the respondents' attitudes and intentions to reduce food waste. The questionnaire also included questions about single-use plastics, waste collection and time use, although that has been excluded from this paper for brevity.

\subsection{Study Site, Sampling Size and Analytical Approach}

Statistics from 2018 indicate that Hanoi [19] has an area of $3358.59 \mathrm{~km}^{2}$ and a population of 7,852,600, including an urban population of 3,847,300 and suburban population of $3,978,300$. Population density is 2338 persons $/ \mathrm{km}^{2}$, but is particularly high in 12 urban districts where the density is 11,468 persons $/ \mathrm{km}^{2}$. In addition, there are hundreds of thousands of non-residents and labourers from other provinces earning their living in Hanoi.

To select the survey sites, the research team used a random stratified sampling method. Firstly, the team divided Hanoi into two major areas - an urban area (12 districts, 1 town) and a rural area (17 districts) - and conducted surveys in both areas. Following the sample size calculation formula developed by Yamane [33] to determine sample size and considering the budget and availability of human resources for the survey, the survey's confidence level was set at $95 \%$ with a precision level at $7 \%$ and an appropriate sample size of 204. After accounting for missing data, a total of 252 responses were received. Secondly, the team chose six out of the 13 districts and towns in the inner city area of Hanoi as representative of the urban area, namely the districts of Long Bien, Nam Tu Liem, Thanh Xuan, Ha Dong, Cau Giay, and Ba Dinh. In the rural area, the team selected six out of 17 rural districts in the suburban area, namely Dong Anh, Thanh Tri, Thach That, Quoc Oai, Gia Lam, and Ung Hoa. Thirdly, the team selected one ward or commune in each district to survey in consideration of how representative it was in providing a picture of the entire city and its accessibility. Lastly, the team randomly selected 20 to 21 households in each ward or commune to survey.

Twelve trained investigators visited the wards or communes and carried out personal interviews with the residents there, rather than requesting that respondents complete the surveys on their own. This style of conducting the survey resulted in highly accurate responses with excellent completion rates.

Using the collected data, the team developed a database in Microsoft Excel on daily food and food waste-related practices in households. A non-parametric $t$-test (Mann-Whitney $U$ test) was conducted using SPSS (Statistical Package for the Social Sciences) software to clarify the differences between urban and rural areas. The results of the survey are described in detail below.

\section{Results of the Survey and Discussion}

\subsection{Attributes of Respondents}

Table 1 provides a detailed composite of the respondents, including gender, age, occupation, education and household income. Since the questionnaire survey was conducted through personal interviews, collection and response rates are nearly 100\%. In total, the team collected primary data from 252 individuals (118 in the urban area and 130 in the rural area with four non-responses) comprising 92 males and 156 females. Ages are distributed along a range of 20 to over 60 years of age, with the largest group falling between 30 to 39 years of age (41\%). The educational level of the sample varies 
from primary school to post-graduate degrees, and out of these, 91 respondents have graduated university and 51 have a master's degree or higher. Monthly household income ranges from below 2 million to over 300 million VND. Among them, 165 respondents (66\%) earn 10-50 million VND. The sample provides a diverse picture of the residents in Hanoi; the majority of respondents are employed as government officers (31\%) and company employees $(25 \%)$, followed by those engaged in self-employment $(20 \%)$, farming $(6 \%)$, and day labour $(4 \%)$, with the remainder comprising full-time housewives, students, part-timers, the unemployed (including pensioners), and others.

Table 1. Characteristics of respondents $(n=252)$.

\begin{tabular}{|c|c|c|}
\hline & & Number of Respondents \\
\hline \multirow{2}{*}{ Location } & Urban area & 118 \\
\hline & Rural area & 130 \\
\hline \multirow{2}{*}{ Gender } & Male & 92 \\
\hline & Female & 156 \\
\hline \multirow{6}{*}{ Age } & $\leq 19$ & 0 \\
\hline & $20-29$ & 39 \\
\hline & $30-39$ & 104 \\
\hline & $40-49$ & 56 \\
\hline & $50-59$ & 28 \\
\hline & $\geq 60$ & 18 \\
\hline \multirow{10}{*}{ Occupation } & Company employee & 64 \\
\hline & Self-employed & 50 \\
\hline & Day labourer & 11 \\
\hline & Part-timer & 4 \\
\hline & Full-time housewife & 8 \\
\hline & Farmer/Agriculturist & 16 \\
\hline & Government officer & 77 \\
\hline & Student (university, junior college, etc.) & 7 \\
\hline & Unemployed (including pensioners) & 7 \\
\hline & Others & 8 \\
\hline \multirow{7}{*}{ Education } & No schooling & 0 \\
\hline & Primary school & 6 \\
\hline & Lower secondary school & 38 \\
\hline & Upper secondary school (High school) & 27 \\
\hline & Vocational or technical university & 35 \\
\hline & University & 91 \\
\hline & Master's degree or higher & 51 \\
\hline \multirow{6}{*}{ Household income } & $<2$ million $\mathrm{VND} /$ month & 4 \\
\hline & 2-5 million VND/month & 11 \\
\hline & 5-10 million VND/month & 63 \\
\hline & $10-50$ million $\mathrm{VND} /$ month & 165 \\
\hline & 50-100 million VND/month & 7 \\
\hline & $\geq 100$ million VND/month & 2 \\
\hline
\end{tabular}




\subsection{Self-Reported Generation of Food Waste in Households}

The total amount of food waste generated in households averages $1192 \mathrm{~g} / \mathrm{day} / \mathrm{household}$ in urban areas and $1694 \mathrm{~g} /$ day/household in rural areas. However, at a 5\% significance level, there was no significant difference between urban and rural areas. When considering the average number of members in a household (4.2 persons/household in urban areas and 4.0 persons/household in rural areas), food waste generation is adjusted to $285 \mathrm{~g} / \mathrm{day} /$ person in urban areas and $423 \mathrm{~g} / \mathrm{day} / \mathrm{person}$ in rural areas. Cooking waste generated during the processing and preparation of meals, such as peels, scraps, corn stub, and bones, accounts for more than $70 \%$ of the total food waste generated (Table 2). While the amount of edible food wasted (leftovers and untouched food) is relatively low in both urban and rural areas, a report by Natural Resources Defence Council found that an average of $0.23 \mathrm{~kg}$ of food per person was wasted per day in households in three U.S. cities (Denver, Nashville, and New York), which contained more than two-thirds (68\%) of edible food [34]. WRAP [35] reports that the average amount of food wasted per person per day was $0.42 \mathrm{~kg}$ in the United Kingdom in 2015, which included $0.30 \mathrm{~kg}$ per person per day from household waste and $0.13 \mathrm{~kg}$ per person per day from supply chain waste. According to official data by the Tokyo Metropolitan Government in 2012, the average amount of food wasted per person per day was around $0.39 \mathrm{~kg}$, which included $0.20 \mathrm{~kg}$ from household waste and $0.19 \mathrm{~kg}$ from supply chain waste [12]. Although data is not directly comparable because of differing definitions of food waste and the methods employed in estimating, it is clear that the total amount of food waste generated in Hanoi is on the same high level as the average in many developed cities and countries.

Table 2. Amount of food waste generated in households.

\begin{tabular}{lccc}
\hline \multicolumn{1}{c}{ Average Amount (g/Day/Household) } & Urban Area & Rural Area & Total \\
\hline Cooking waste (generated during processing and & 864 & 1187 & 1043 \\
preparation of meals) & 163 & 224 & 199 \\
Leftovers from cooked staple foods (rice, bread, etc.) & 87 & 134 & 113 \\
Leftovers from cooked dishes & 38 & 41 & 40 \\
Untouched food such as food that has passed the & 38 & 60 & 51 \\
"sell-by date" or "use-by date" & 2 & 48 & 26 \\
Tea leaves and coffee grounds & 1192 & 1694 & 1443 \\
Others & & \\
Total & &
\end{tabular}

\subsection{Current and Future Eating Habits}

This survey offers a portrait of the balanced diet of a segment of Hanoi's population and provides a glimpse into the types of ingredients consumed by respondents, including meat (pork, chicken), eggs, fish and seafood, dairy products, vegetables, and fruits. This paper focuses on eating habits in terms of the respondents' frequency of consumption and settings in which they partake of meals, such as dining out, consuming store-bought, ready-to-eat meals at home, and eating home-cooked meals at their place of residence.

Table 3 shows the number of times respondents eat each day. It shows that staple foods can be found on the plates of respondents in rural areas about three times a day on average, compared to two times a day in urban areas. People in both urban and rural areas consumed rice, noodles, bread, vegetables, and fruits more than once a day. There was a significant difference between urban and rural areas in regard to staple foods, other grains/cereals, pork, other meats, milk/dairy products, desserts, and dietary supplements at a $5 \%$ level of significance in the Mann-Whitney U-test.

The average number of times respondents eat in, consume ready-made meals, and eat out each day is shown in Table 4, among which showing a significant difference between urban and rural areas at the $5 \%$ level of significance by Mann-Whitney U-test. People in urban areas ate out 0.5 times per day, a figure that is higher than those in rural areas ( 0.3 times per day), while people in rural areas ate in 2.3 times per day, which is more frequent than respondents in urban areas (1.7 times per day). 
Both residents in rural and urban areas consumed ready-made meals relatively infrequently. There is a strong indication that people eat at home more often than dining outside or consuming ready-made meals, in comparison with cities in other countries, such as Bangkok [12].

Table 3. Number of times respondents eat each day.

\begin{tabular}{cccc}
\hline & \multicolumn{3}{c}{ Average Times a Day } \\
\cline { 2 - 4 } & Urban & Rural & Total \\
\hline Staple foods (rice, noodle, bread) & 1.9 & 2.7 & 2.3 \\
\hline Other grains/cereals * & 0.4 & 0.4 & 0.4 \\
\hline Beans and pulses/processed beans & 0.4 & 0.4 & 0.4 \\
\hline Pork * & 0.7 & 1.1 & 0.9 \\
\hline Chicken & 0.4 & 0.4 & 0.4 \\
\hline Beef & 0.4 & 0.3 & 0.4 \\
\hline Other meats * & 0.4 & 0.1 & 0.2 \\
\hline Eggs & 0.5 & 0.5 & 0.5 \\
\hline Fish and seafood & 0.4 & 0.5 & 0.5 \\
\hline Milk/dairy products * & 0.9 & 0.7 & 0.8 \\
\hline Vegetables * & 1.7 & 2.1 & 1.9 \\
\hline Fruits & 1.4 & 1.3 & 1.3 \\
\hline Sweets and desserts * & 0.7 & 0.4 & 0.5 \\
\hline Dietary supplements * & 0.4 & 0.3 & 0.3 \\
\hline * Mann-Whitney U-test: $p<0.05$. & \\
\hline
\end{tabular}

Table 4. Average number of times respondents eat in, consume ready-made meals and eat out each day.

\begin{tabular}{cccc}
\hline & \multicolumn{3}{c}{ Average Times a Day } \\
\cline { 2 - 4 } & Urban & Rural & Total \\
\hline Eat out $^{*}$ & 0.5 & 0.3 & 0.4 \\
\hline Consume ready-made meals $^{*}$ & 0.3 & 0.2 & 0.2 \\
\hline Eat in * & 1.7 & 2.3 & 2.0 \\
\hline * Mann-Whitney U-test: $p<0.05$.
\end{tabular}

Dietary changes over the past five years and intentions in terms of eating habits are shown in Figure 2. More than half of the respondents plan to maintain their current eating habits in the future. In particular, a greater number of people in the urban area plan to cook and eat in more often. This indicates that most people intend to continue eating in more often in both urban and rural areas. Responses to the survey also showed that health and food safety is a key factor in decision-making on diet amongst consumers in Hanoi, which may be a springboard for identifying ways that consumer behaviour can be adapted to decisively reduce food waste [28].

\subsection{Frequency and Reasons for Food Waste in Diverse Settings}

Figures 3 and 4 illustrate the frequency with which food waste is generated when eating at home and dining out. More than half of the respondents in urban and rural areas indicated that they rarely or never waste food when eating at home. This is in contrast to a shift in habits when dining out, with almost $50 \%$ of urban residents responding that they often waste food in these settings. While rural residents still waste less food on average than their counterparts in urban areas, the percentage of people in rural areas who indicated that they sometimes waste food when they eat out is almost twice as high as when they eat at home. 


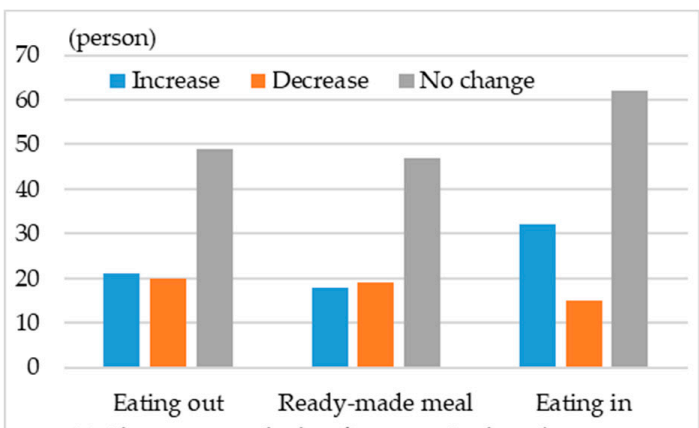

(a) Changes over the last five years in the urban area

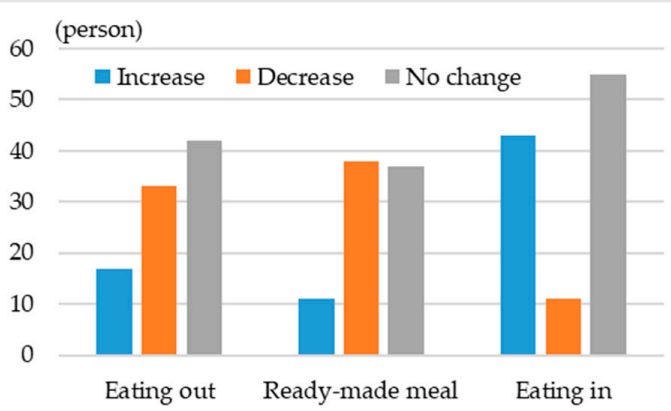

(b) Tendencies in the coming years in the urban area

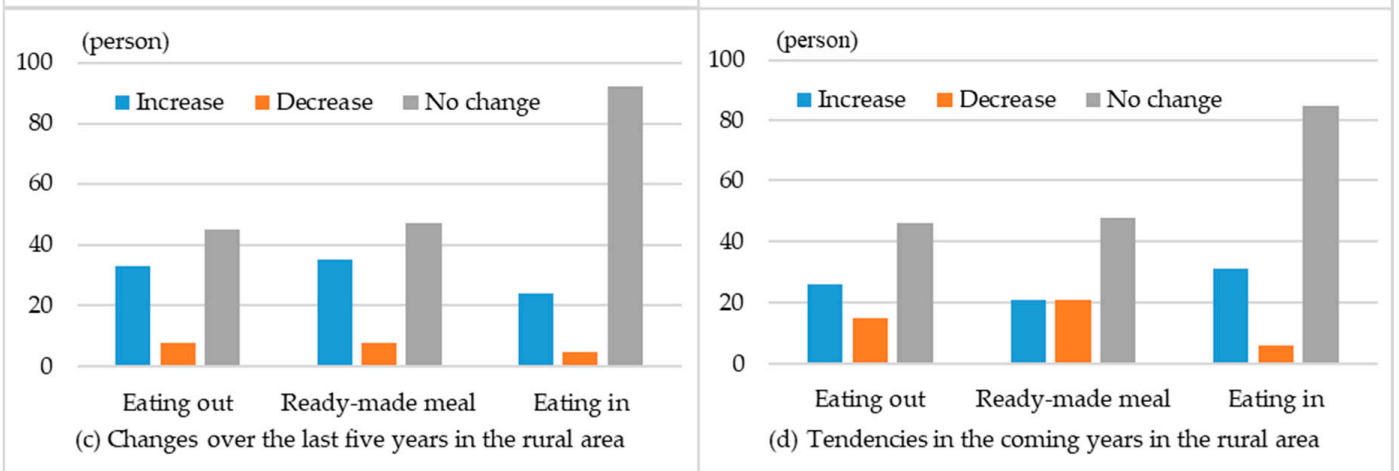

Figure 2. Dietary changes and intended future eating habits in urban and rural areas.

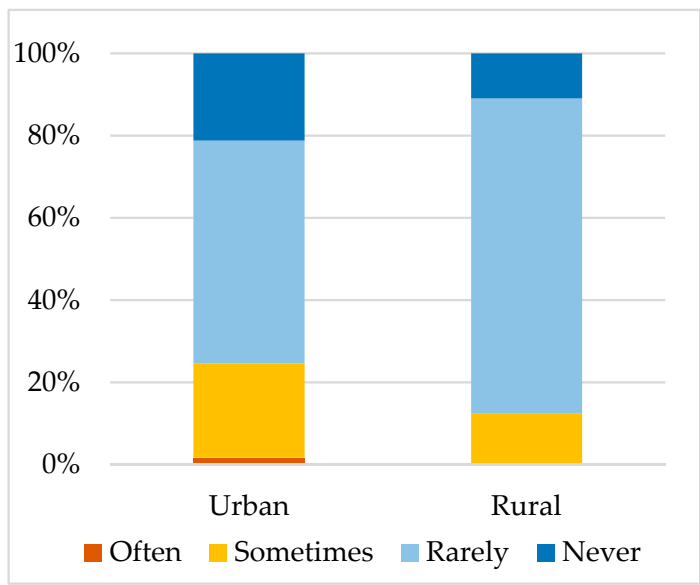

Figure 3. Food wastage when eating at home in urban and rural areas.

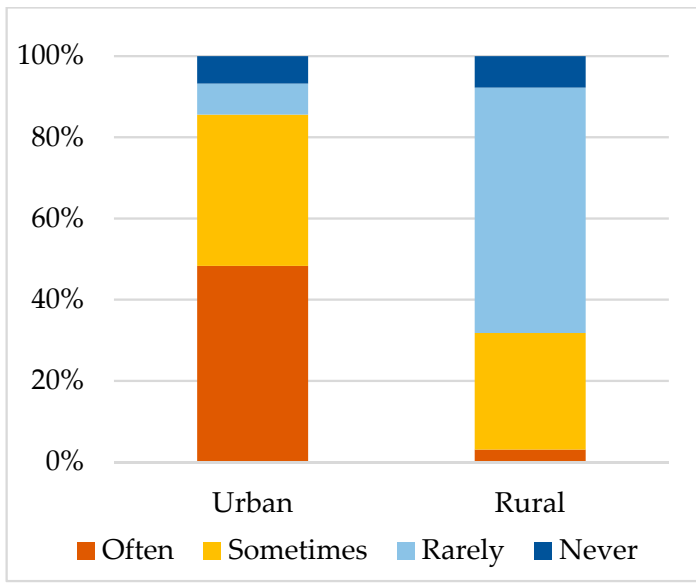

Figure 4. Food wastage when eating out. 
At home, the prevailing reason for the generation of food waste in both urban and rural areas is that food had passed its "use-by" date, followed by deteriorating quality (Figure 5). Although labels that indicate expiration dates generally reflect the estimated date that food is at peak quality or taste, it rarely indicates the actual safety of a food product, and may result in the unnecessary disposal of large amounts of food that can still be consumed.

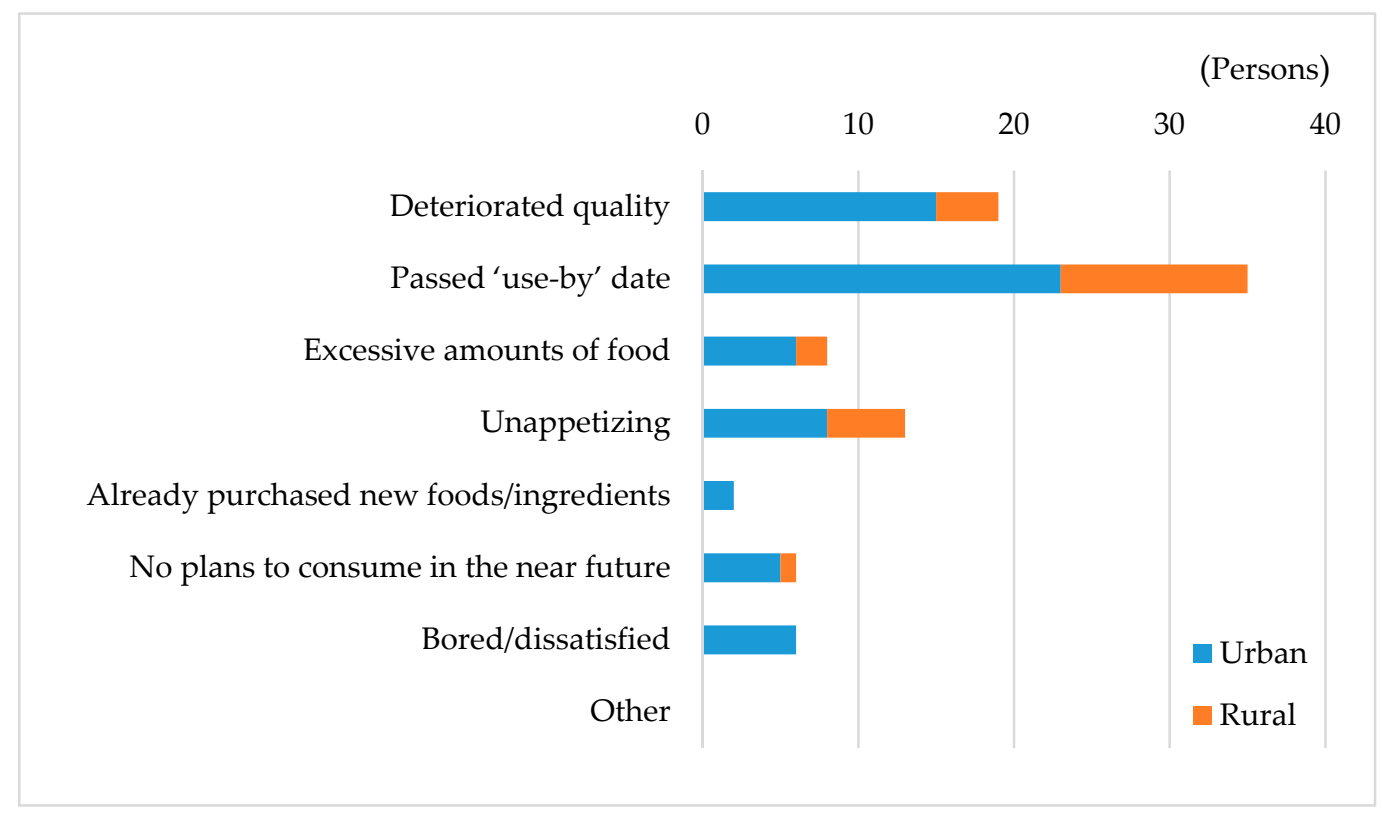

Figure 5. Reasons for food waste generated at home.

The top reasons for food waste when eating out were that people ordered too much and servings were too large (Figure 6). Respondents also cited dislike or dissatisfaction with the taste or that they preferred more variety as reasons for leftover food.

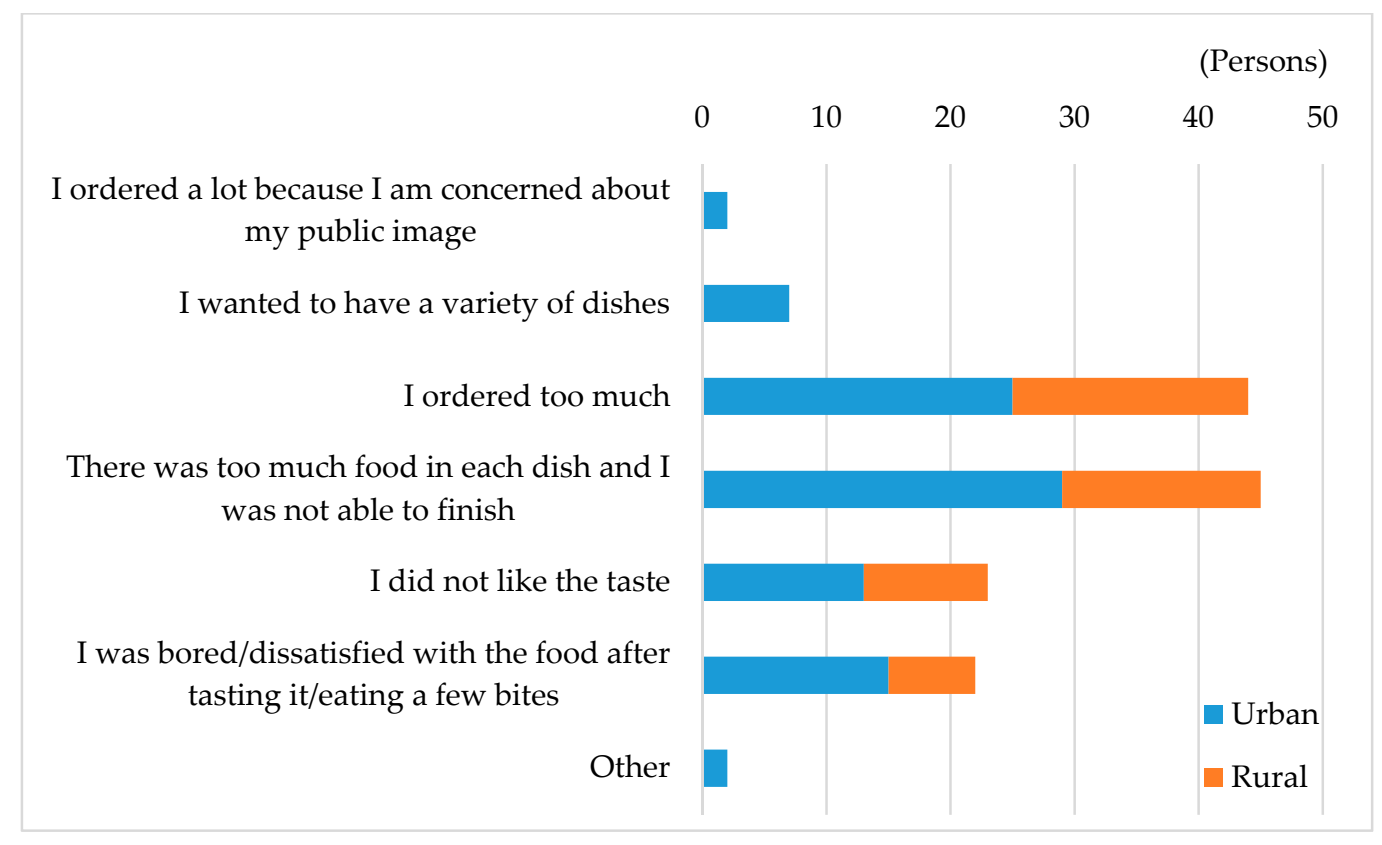

Figure 6. Reasons for food waste when eating out. 


\subsection{Waste Separation Habits in Households}

Data obtained from respondents on methods to manage and dispose of food waste show that more than half of respondents (58\%) did not separate food waste before disposal, while $24 \%$ separated food waste for sanitary reasons, and less than $20 \%$ actively separated and recycled food waste completely (Figure 7). Furthermore, the separation and reuse/recycling rate is higher in rural areas than urban areas for leftovers of cooked food/dishes and untouched food, in particular.

(a) Urban

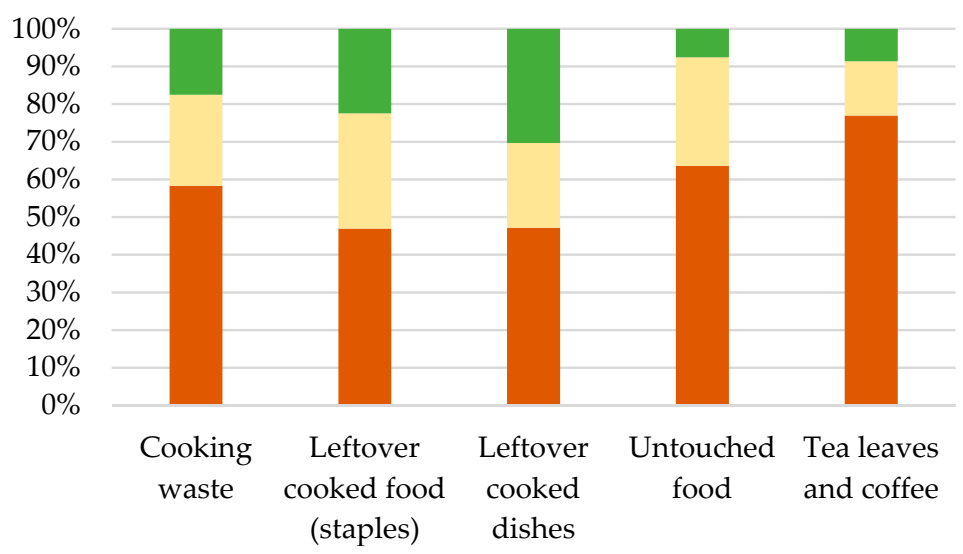

- Separation and then reuse/recycling

Separation and then disposal

Disposal without separation

(b) Rural

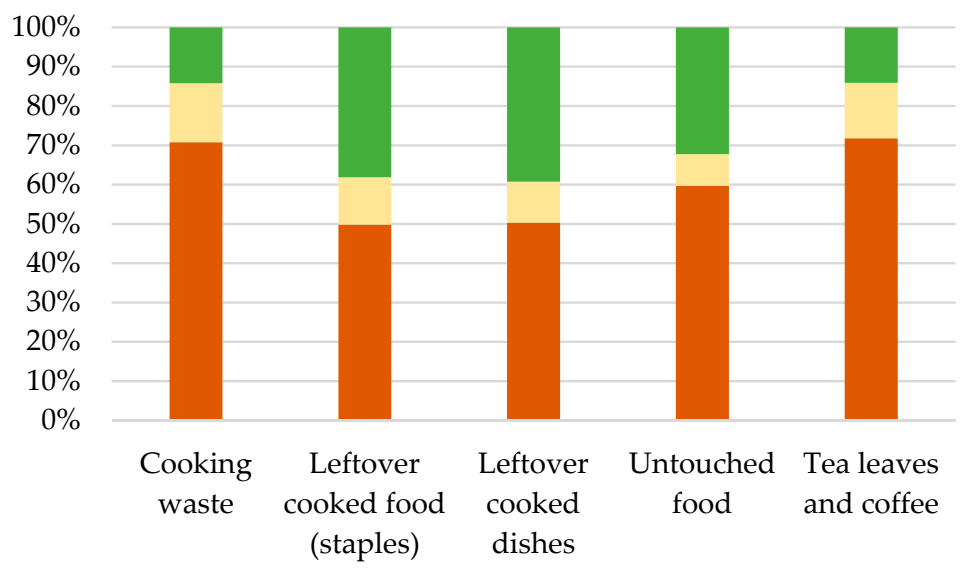

- Separation and then reuse/recycling

Separation and then disposal

Disposal without separation

Figure 7. Methods of managing/disposing food waste in (a) urban and (b) rural areas.

The survey shows differences in the way that people in urban and rural areas separate and then reuse or recycle food waste (Figure 8). In urban areas, the majority of respondents share leftover food with other people, while in rural areas, food waste is used as animal feed and for other purposes. Follow-up interviews found that in urban areas, people look to acquaintances, such as neighbours who have pets like dogs or cats, or vendors in nearby markets who raise animals like pigs, for example, and share food that has been left over from meals, such as cooked rice, meat, and fish. In rural areas where most households raise livestock, it is easier to reuse leftovers directly as animal feed.

\subsection{Outlook of Respondents on Reducing Food Waste}

The majority of respondents in both rural and urban areas are quite willing to reduce food waste (Figure 9), which is evident in their efforts to reuse or recycle food waste. Only a few indicated that they have no plans to reduce food waste. Respondents were considering possible ways to reduce food waste, including limiting the amount of food cooked, reducing the amount of food ordered when eating out, regularly checking food in their refrigerators or cupboards, trying to avoid over-shopping or 
purchasing in bulk, checking "use-by" dates regularly, planning in advance for each meal, and figuring out how to make other dishes from leftover food (Figure 10).

(a) Urban

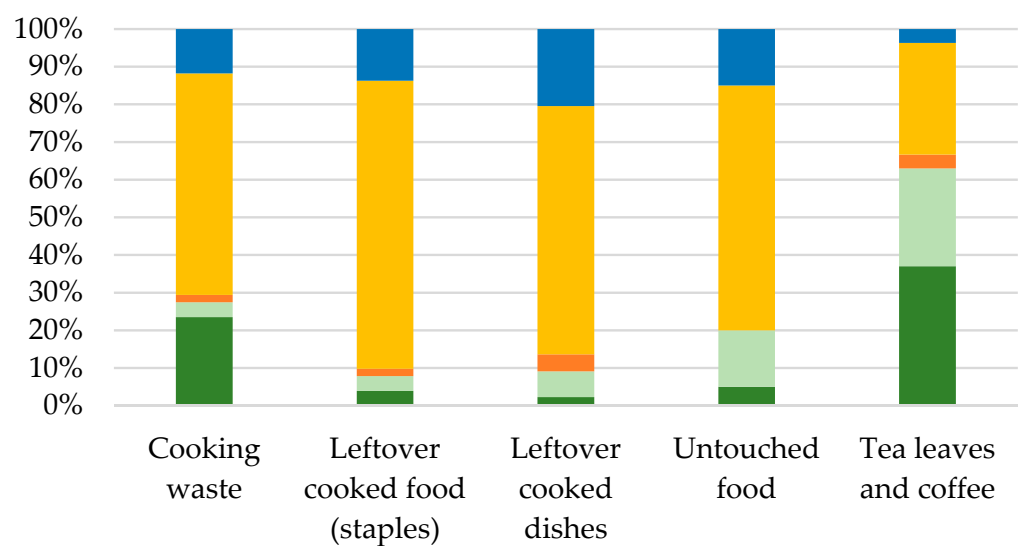

- Other (animal feed)

Give to other people

Bring to waste bank

Community composting

- Household composting

(b) Rural

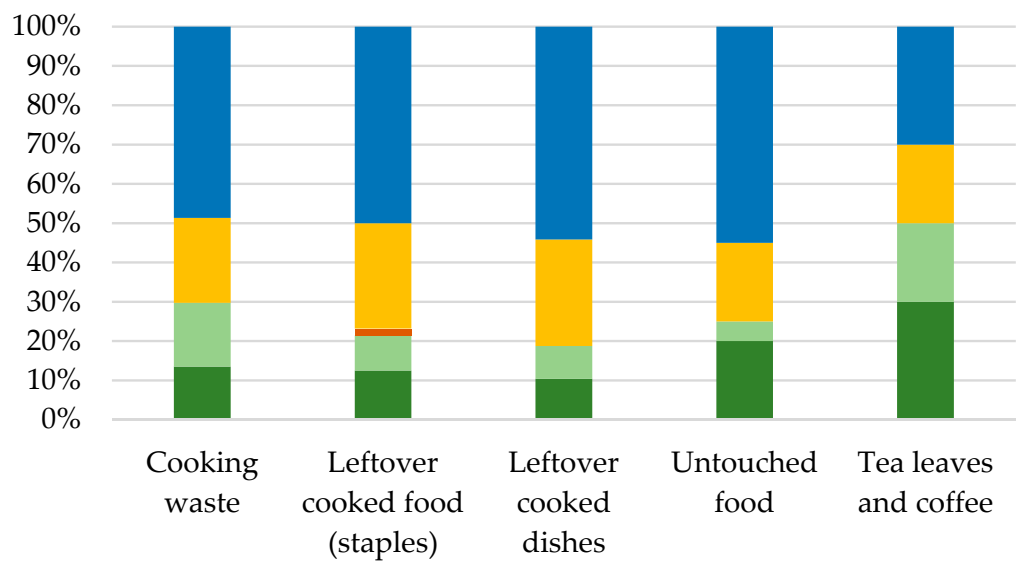

口 Other (animal feed)

Give to other people

Bring to waste bank

Community composting

- Household composting

Figure 8. Reuse/recycling methods by respondents who answered that they separate, reuse, and recycle waste. (a) urban areas; (b) rural areas.

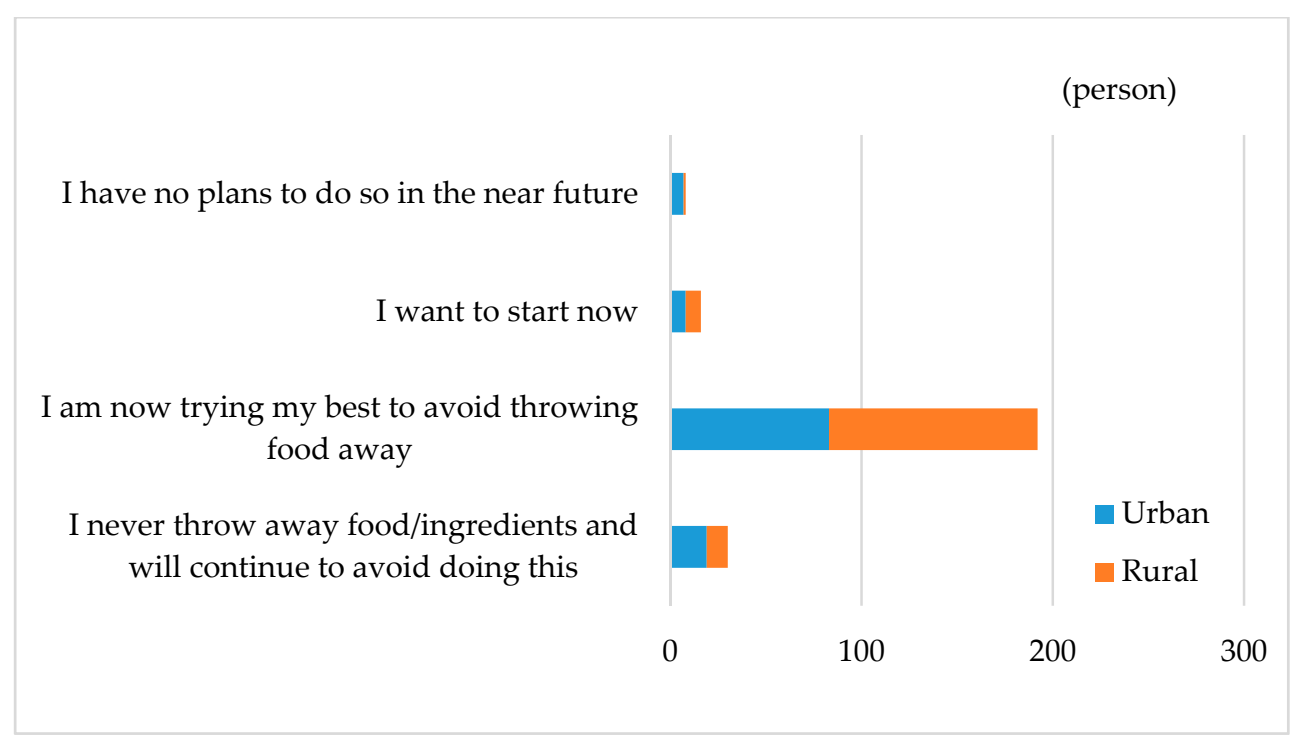

Figure 9. Respondents' efforts to reduce food waste. 


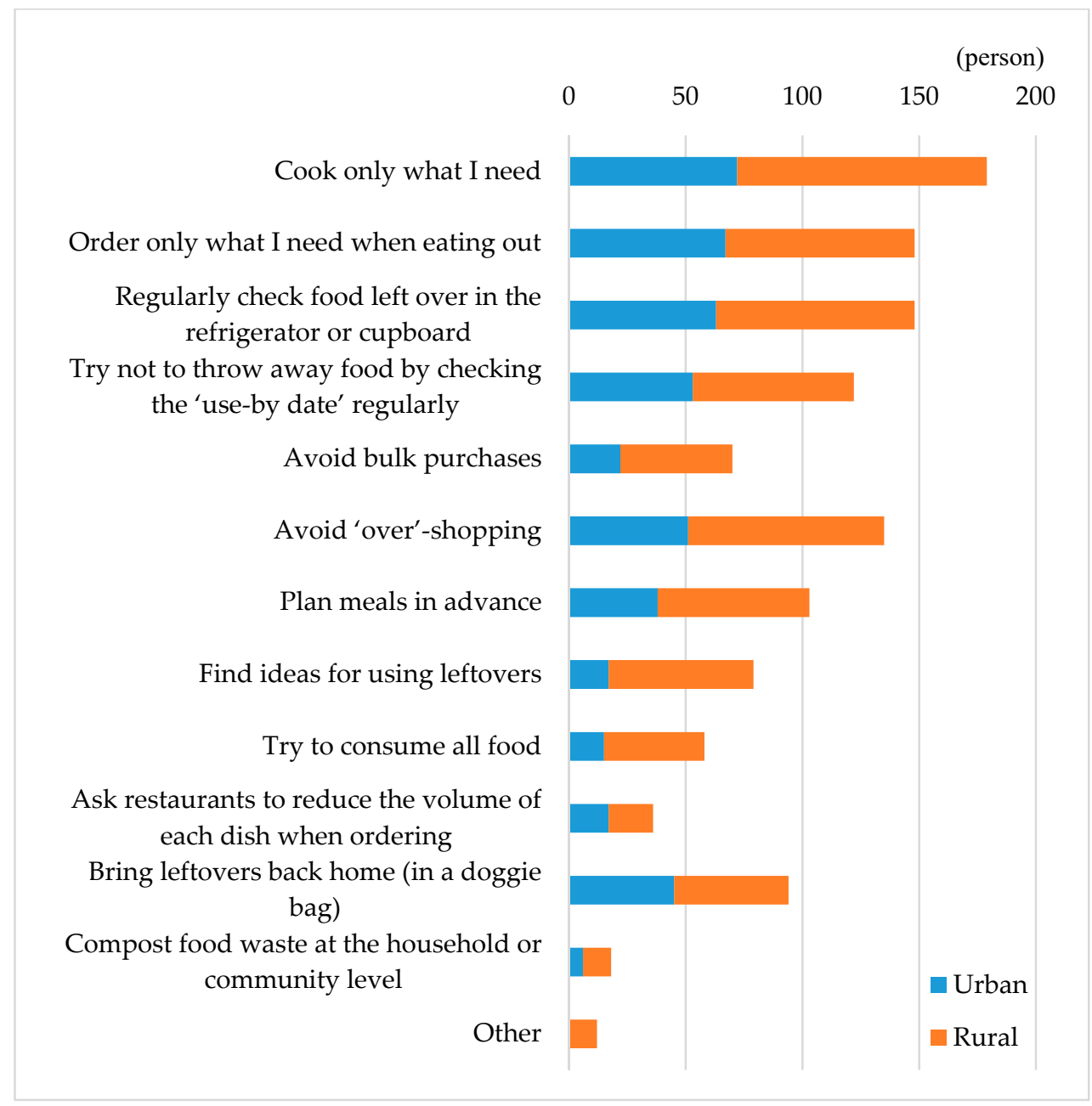

Figure 10. Respondents' intentions to reduce food waste.

Although earlier research suggests a tenuous correlation between people's attitudes in reducing food waste and actual behaviour [36,37], the results from this survey suggest the importance of identifying potential ways that consumers can apply promising methods to reduce food waste more easily than current practices.

\section{Policy Recommendations and Potential Actions}

The issue of food waste is considered to be a key to helping all countries achieve targets decided through international consensus, including the Paris Agreement and the 2030 Agenda (SDGs). A growing number of studies illustrate the ways in which households are embedded within broader social-economic contexts that create the paths through which food becomes waste and call for a more "holistic" policy approach that engages fully with the complexity of food waste across multiple scales $[27,28,38]$. Many unaddressed issues and challenges are obstacles that lie in the path to solutions to prevent and reduce the amount of food waste generated. Based on the results of the survey, some high-priority recommendations that may have implications for national and local policies are as follows:

(1) Development of comprehensive food waste policies to address the issue of food waste along the entire food supply chain

Food waste is still considered part of MSW in Vietnam. The country's policies related to food waste are disconnected and disjointed, and therefore are unable to cover the entire food supply chain. 
However, the issue of food waste is not a simple end-of-life waste issue. The impact of waste policies on food waste reduction has been estimated as negligible by the European Commission [39]. The scholarly discussion on food waste has gradually shifted from a "waste" angle into a more holistic approach towards the development of a sustainable food system targeting the different stages of the food supply chain [40].

The European Commission has adopted a Circular Economy package which aims at helping European businesses and consumers transition toward more sustainable resource use [41]. To achieve the SDG 12.3 target, it is critical to develop a specific, comprehensive food waste policy covering the entire food supply chain based on the coordination of overlapping authority among related ministries. Several ministries are responsible for different stages of the food supply chain in relation to food waste issues. These include the Ministry of Agriculture and Rural Development in the agriculture production stage and food processing and manufacturing stage, the Ministry of Industry and Trade for food processing, wholesalers and retailers, and the Ministry of Natural Resources and Environment for issues that incorporate a waste management perspective. Policy coordination through the development of an inter-ministerial taskforce on food waste along the food supply chain of production, processing, storage, transportation, commercialisation, and household settings could help solve administrative challenges at the policymaking level.

(2) Development of a practical food waste management system based on household separation and collection as well as "recycling loop" schemes to support the utilisation of recycled food waste products, especially in rural areas

In investigating food waste practices in households in Hanoi and relevant policies on food waste in Vietnam, this survey found the letter of the law lacking in options for the realistic implementation of policies, resulting in both a rise in the amount of food waste and an increase in MSW cross-contaminated with food waste sent to landfills. A case in point: although Vietnam set goals for ambitious waste management systems, recycling, and separation of waste at source in its National Strategy on Integrated SWM in 2009, the results of the survey indicated that waste is not being separated out at the household level and collection systems for separated waste have not been implemented. As a result, the target for 2015 has not been achieved, and other targets including those in the revised strategy still face an overabundance of challenges in view of the current state of SWM in the country.

Considering that the results of the survey showed that people in Hanoi often dine out and are willing to eat at home, and cooking waste generated during the preparation of meals covers more than $70 \%$ of the total, there is some indication that the household is a primary source of generated food waste. While the cooperation of residents in separating waste at source is vital, the development of practical food waste household separation and collection systems is also crucial in identifying appropriate solutions for food waste management as well as reducing the actual costs of waste management.

In the survey, residents expressed concern about the separate collection of waste. In this context, it is also important to establish a collection service that supports waste separation at source. It is necessary for the Hanoi government to fully understand the details of informational, educational, economic, and regulatory methods in national policies to accurately prioritise policy methods, identify effective policy measures in education and public awareness, and carefully design the entire waste management system. For example, collecting various types of waste on different days with high priority placed on fully-separated food waste and other recyclable waste, and setting different collection fees for recyclables and non-recyclables would act as a good economic incentive for household segregation [42].

There are no schemes in place that support the use of recycled products, even as regulations contain specific reference to integrated MSW facilities and suggestions for composting organic waste. A variety of technologies exist that can be leveraged in finding alternative paths for using food waste, such as animal feed processing, composting, and anaerobic digestion, with each demonstrating its own merits and demerits $[40,43]$. What Hanoi must consider is the development of a sustainable market mechanism that is predicated on local conditions to cover initial investment and running costs for 
food waste recycling technologies, production of commodities from recycled products, and creating demand for recycled products such as bio-fertiliser, animal feed, or biogas.

Furthermore, the results of the survey found that self-reported food waste generation in households in rural areas is relatively high, and less than $10 \%$ of food waste is reused/recycled as animal feed. In light of the high food waste generation rate and large population, it is important to strengthen food waste management in rural areas even with low waste collection and treatment rates.

\section{(3) Development of a shared platform for collaboration and intervention}

The results of this survey demonstrate that in urban areas of Hanoi, people have adopted the habit of reusing leftover food directly and indirectly as animal feed. A shared platform would make it easier for people to identify others nearby who have pets or raise animals and supply them with food left over from their own meals, thereby encouraging collaboration among households. Furthermore, with this type of community intervention, such platforms for sharing food as well as leftovers would provide an option for connecting practices implemented by individuals, allow them to share their experiences with $3 \mathrm{R}$ activities, and eventually expand practices outside of smaller pilot areas. Also, digital platforms such as food rescue apps can be used as a mechanism for organising stakeholders to encourage their active participation in the process.

(4) Reduction in portions and encouraging consumers to use surplus food at home

The survey shows that the top reasons cited for food waste when eating out were over-ordering and excessive portions. One way to prevent and encourage measures to reduce food waste in food courts and restaurants would be to cut portion sizes and encourage customers to take leftovers home. Previous studies have identified a better estimation of portion sizes as one of the most promising actions to avoid wasting food [44-46]. Serving small portions or offering a variety of options for portion sizes puts consumers in the driver's seat when deciding the size of their meals. Moreover, a relatively easy game-changer is repositioning social norms to encourage consumers to use doggy bags to take leftover food home.

\section{(5) Creation of uniform standards and a consensus on labels indicating food expiration dates}

The results of the survey show that the prevailing reason for the generation of food waste at home is that food had passed its "use-by" date. Concerns about food safety and foodborne illnesses, together with a desire to eat fresh food are prominent reasons for the generation of food waste [47]. Instituting policies for uniform standards will help reduce confusion around expiration dates, such as when food has been manufactured/produced/packed, when it must be sold/used by/best-used-by or when it expires, and reduce food waste generated by households. The public must be kept informed not only about actual policies, but what implications these policies have on a day-to-day basis. Meanwhile, the review and elimination of unnecessary food safety standards has the potential to reduce unnecessary food waste. In addition, raising awareness on sustainable lifestyles, especially of the middle class, will help guide people in using their own sense to form a more nuanced assessment of edibility and may reduce food waste generation in households. The application of intelligent packaging indicating "use-by" dates in combination with a dynamic system that details the real state of the food inside packaging may also be considered as a way to significantly reduce food waste [48].

(6) Promotion of sufficiency strategies to save food, reduce food waste and maintain healthy lifestyles

Policies aimed at changing consumption behaviours are designed according to efficiency, consistency, and sufficiency principles. Sufficiency strategies focus on the demand side by emphasising consumers' responsibilities to restrict the consumption of natural resources and the amount of food consumed [49]. Although sufficiency policies are not very popular due to the fear that they may impede individual well-being and quality of life, it would be a promising approach for improving the 
sustainability of the modern food system if conducted carefully and related to appropriate motives for changes [50]. In fact, sufficiency strategies are not one-way reductions, but keep amounts at "suitable" and "appropriate" levels. These strategies could help consumers who overconsume resources to not only reduce food waste and save natural resources, but maintain healthy lifestyles and well-being. The survey found that health is a key contributor to decisions on diet among consumer in Hanoi, and the government may be able to promote the alignment of government and citizens' actions based on sufficiency strategies to improve people's health and well-being while addressing food waste issues, to create a more sustainable society.

\section{Conclusions}

This paper uses Hanoi as a case study to clarify the current situation and trends in food consumption and food waste generation in households, examines ways in which consumers generate food waste, reviews relevant food waste policies and strategies already in place, and provides prescriptions for preventing and reducing food waste. This study found that (1) the level of food waste generation is high in Hanoi even when compared with developed countries, but is not being managed appropriately; (2) while the national government has put a number of laws, legislation, and strategies into effect and outlined ambitious targets for waste management, there is a lack of implementation at the local level; (3) both urban areas and rural areas in Hanoi are a major source of food waste; (4) there is a strong indication that people eat at home more often than dining outside or consuming ready-made meals, which might be a reason for the high generation of food waste by households and the high percentage of cooking waste in the total amount of food waste generated in households; (5) people rarely waste food when eating at home, while food waste tends to be generated more when dining out; (6) the main reasons for wasting food at home are that food has passed its "use-by date" and is seen to be of "deteriorating quality," while the top reasons for wasting food when eating out are that people over-order and that serving sizes are too large; (7) less than $20 \%$ of food waste is separated out for reuse and recycling, with the remainder is disposed and transported to landfills; (8) in urban areas, the majority of respondents offer leftover food to other people, while in rural areas, food waste is used as animal feed and for other purposes; and (9) most respondents are willing to reduce, reuse, and recycle food waste so interventions at the consumer level may hold promise in encouraging consumers to practice ways to reduce food waste.

Based on an analysis of the results of this survey, policy implications have been proposed for national and local policymakers and practitioners to consider as potential avenues to explore to reduce waste, including the (1) development of comprehensive food waste policies to address the issue of food waste along the entire food supply chain; (2) development of a practical food waste management system based on household separation and collection as well as "recycling loop" schemes to support the utilisation of recycled food waste products, especially in rural areas; (3) development of a shared platform for collaboration and intervention; (4) reduction in portions and encouraging consumers to use surplus food at home; (5) creation of uniform standards and a consensus on labels indicating food expiration dates; and (6) promotion of sufficiency strategies for saving food, reducing food waste, and maintaining a healthy lifestyle.

The issue of food waste is considered to be vital for all countries to achieve targets decided through international consensus, including the Paris Agreement and the 2030 Agenda (SDGs). The Vietnamese government is facing mounting pressure to establish a suitable waste management system. At the same time, Vietnam is an agriculture-based economy with a potentially high level of demand for bio-fertiliser, such as compost and fermented liquid manure by anaerobic digestion. Two decrees (Decree 109/ND-CP on Organic Agriculture issued in 2018 and Decree 84/ND-CP on Regulations on Fertiliser Management issued the following year) encourage the practice of organic agriculture and set out what constitutes an organic fertiliser. Collaboration between peripheral villages and towns could help drive a transition from conventional waste management to innovative resource management and to a sustainable food production-consumption system, although tremendous challenges remain. 
It is clear that the data presented in this study is relatively uncertain due to the limited number of samples as well as limitations in self-reporting measures. However, this is the first attempt to link food waste to waste producers in urban and rural areas in Hanoi and to gain an understanding of the situation of food waste generation and the diversity of factors that can influence food waste behaviours at the household level in order to improve waste management systems and policies to reduce food waste. Future research should aim to validate these self-reporting measures with more objective techniques for data collection, and link food waste generation in households to both the food and waste systems to draw a picture of the overall image of food waste generation. Furthermore, the complexity of the food waste issue requires collaboration among different disciplines to bring the grainy picture of the reasons why consumers generate food waste into clearer focus. Finally, to achieve SDG target 12.3 of halving food waste at the consumer level by 2030, ensuring harmonised data collection on food waste remains an issue in Asia, and practical policies, strategies, and actions on source reduction is an area that can be considered for future study.

Supplementary Materials: The following is available online at http://www.mdpi.com/2071-1050/12/16/6565/s1, Questionnaire: Survey on Personal Lifestyles in Viet Nam.

Author Contributions: Conceptualization, C.L.; Data curation, T.T.N. and C.L.; Formal analysis, C.L. and T.T.N.; Methodology, C.L.; Validation, T.T.N.; Visualization, C.L.; Writing—original draft, C.L. All authors have read and agreed to the published version of the manuscript.

Funding: This research was supported by the Environment Research and Technology Development Fund (S-16) of the Environmental Restoration and Conservation Agency of Japan "Policy Design and Evaluation to Ensure Sustainable Consumption and Production Patterns in the Asian Region" (2016-2020), and the IGES SRF Fund 2020.

Acknowledgments: The authors would like to thank Phuong Anh Duong Thi and Thu Ha Nguyen Thi for their technical assistance with the questionnaire survey, and would also like to express gratitude to the referees for their useful comments.

Conflicts of Interest: The authors declare no conflict of interest.

\section{References}

1. Food and Agriculture Organization of the United Nations (FAO). The state of Food and Agriculture; FAO: Rome, Italy, 2019.

2. Beretta, C.; Stoessel, F.; Baier, U.; Hellweg, S. Quantifying food losses and the potential for reduction in Switzerland. Waste Manag. 2013, 33, 764-773. [CrossRef] [PubMed]

3. FAO. Food Wastage Footprint \& Climate Change; FAO: Rome, Italy, 2015.

4. FAO. Food Wastage Footprint: Full-Cost Accounting; FAO: Rome, Italy, 2014.

5. FAO; IFAD; WFP. The State of Food Insecurity in the World 2015. Meeting the International Hunger Targets: Taking Stock of Uneven Progress; FAO: Rome, Italy, 2015.

6. United Nations. Transforming Our World: The 2030 Agenda for Sustainable Development; UN: New York, NY, USA, 2015.

7. Poore, J.; Nemecek, T. Reducing food's environmental impacts through producers and consumers. Science 2018, 992, 987-992. [CrossRef] [PubMed]

8. Gustavsson, J.; Cederberg, C.; Sonesson, U.; Van Otterdijk, R.; Meybeck, A. Global Food Losses and Food Waste; FAO: Rome, Italy, 2011.

9. Östergren, K.; Gustavsson, J.; Bos-Brouwers, H.; Timmermans, T.; Hansen, O.J.; Møller, H.; Anderson, G.; O'Connor, C.; Soethoudt, H.; Quested, T.; et al. FUSIONS Definitional Framework for Food Waste; EU: Goteborg, Sweden, 2014.

10. Schneider, F. Review of food waste prevention on an international level. Proc. Institutions Civ. Eng.-Waste Resour. Manag. 2013, 166, 187-203. [CrossRef]

11. Sahakian, M.; Shenoy, M.; Soma, T.; Watabe, A.; Yagasa, R.; Premakumara, D.G.; Liu, C.; Favis, A.M.; Saloma, C. Apprehending food waste in Asia: Policies, practices and promising trends. In Routledge Handbook of Food Waste; Routledge: London, UK, 2020; pp. 187-206.

12. Liu, C.; Mao, C.; Bunditsakulchai, P.; Sasaki, S.; Hotta, Y. Food waste in Bangkok: Current situation, trends and key challenges. Resour. Conserv. Recycl. 2020, 157, 104779. 
13. Hansen, A. Meat consumption and capitalist development: The meatification of food provision and practice in Vietnam Geoforum Meat consumption and capitalist development: The meati fi cation of food provision and practice in Vietnam. Geoforum 2018, 93, 57-68. [CrossRef]

14. Rangkuti, F.Y.; Wright, T. Indonesia Retail Foods: Indonesia Retail Report Update 2013; Foreign Agricultural Service: Jakarta, Indonesia, 2013. Available online: https://apps.fas.usda.gov/newgainapi/api/report/ downloadreportbyfilename?filename=Retail\%20Foods_Jakarta_Indonesia_12-13-2013.pdf (accessed on 20 June 2020).

15. Aktas, E.; Sahin, H.; Topaloglu, Z.; Oledinma, A.; Huda, A.K.S.; Irani, Z.; Sharif, A.M.; van't Wout, T.; Kamrava, M. A consumer behavioural approach to food waste. J. Enterprise Inf. Manag. 2018, 31, 658-673. [CrossRef]

16. Goodman, D.S.; Robinson, R. The New Rich in Asia: Mobile Phones, McDonald's and Middle Class. Revolution; Routledge: London, UK, 2013.

17. Reardon, T.; Hopkins, R. The supermarket revolution in developing countries: Policies to address emerging tensions among supermarkets, suppliers and traditional retailers. Eur. J. Dev. Res. 2006, 18, 522-545. [CrossRef]

18. Lee, K.C.L. Grocery shopping, food waste, and the retail landscape of cities: The case of Seoul. J. Clean. Prod. 2018, 172, 325-334. [CrossRef]

19. General Statistics Office of Vietnam. Statistical Yearbook of Vietnam 2018; General Statistics Office: Hanoi, Vietnam, 2019.

20. Vietnam National Administration of Tourism. 2019. Available online: http://vietnamtourism.gov.vn/index. php/items/13462 (accessed on 24 January 2019).

21. World Bank Group. Climbing the Ladder: Poverty Reduction and Shared Prosperity in Vietnam; World Bank. 2018. Available online: http://documents1.worldbank.org/curated/en/206981522843253122/pdf/124916WP-PULIC-P161323-VietnamPovertyUpdateReportENG.pdf (accessed on 12 July 2020).

22. World Bank Group. Ending Poverty, Investing in Opportunity; World Bank. 2019. Available online: http://documents1.worldbank.org/curated/en/156691570147766895/pdf/The-World-Bank-AnnualReport-2019-Ending-Poverty-Investing-in-Opportunity.pdf (accessed on 12 July 2020).

23. World Bank Group. Solid and Industrial Hazardous Waste Management Assessment; World Bank. 2018. Available online: http://documents1.worldbank.org/curated/en/352371563196189492/pdf/Solidand-industrial-hazardous-waste-management-assessment-options-and-actions-areas.pdf (accessed on 20 July 2020).

24. Huong, L.T.; Kawai, K.; Thai, N.T. Physical Composition Analysis of Household Waste in Hanoi, Vietnam. Available online: http://www.gels.okayama-u.ac.jp/management/up_load_files/gakkan/2012_en/2012_en_314.pdf (accessed on 20 July 2020).

25. Kawai, K.; Huong, L.T.; Yamada, M.; Osako, M. Proximate composition of household waste and applicability of waste management technologies by source separation in Hanoi, Vietnam. J. Mater. Cycles Waste Manag. 2016, 18, 517-526. [CrossRef]

26. Aschemann-Witzel, J.; De Hooge, I.; Amani, P.; Bech-Larsen, T.; Oostindjer, M. Consumer-Related Food Waste: Causes and Potential for Action. Sustainability 2015, 7, 6457-6477. [CrossRef]

27. Roodhuyzen, D.M.; Luning, P.A.; Fogliano, V.; Steenbekkers, L.P. Putting together the puzzle of consumer food waste: Towards an integral perspective. Trends Food Sci. Technol. 2017, 68, 37-50. [CrossRef]

28. Schanes, K.; Dobernig, K.; Gözet, B. Food waste matters-A systematic review of household food waste practices and their policy implications. J. Clean. Prod. 2018, 182, 978-991. [CrossRef]

29. Leray, L.; Sahakian, M.; Erkman, S. Understanding household food metabolism: Relating micro-level material flow analysis to consumption practices. J. Clean. Prod. 2016, 125, 44-55. [CrossRef]

30. Sahakian, M.; Saloma, C.; Ganguly, S. Exploring the Role of Taste in Middle-Class Household Practices. Asian J. Soc. Sci. 2018, 46, 304-329. [CrossRef]

31. Soma, T. (Re)framing the Food Waste Narrative: Infrastructures of Urban Food Consumption and Waste in Indonesia. Indonesia 2018, 105, 173-190. [CrossRef]

32. Soma, T. Wasted infrastructures: Urbanization, distancing and food waste in Bogor, Indonesia. Built Environ. 2017, 43, 431-446. [CrossRef]

33. Yamane, T. Statistics, An Introductory Analysis, 2nd ed.; Harper and Row: New York, NY, USA, 1967. 
34. Berkenkamp, C.; Phillips, J. Modeling the potential to increase food rescue: Denver, New York and Nashville. Nrdc 2017, 41, R-17-09-B. Available online: https://www.nrdc.org/sites/default/files/modeling-potentialincrease-food-rescue-report.pdf (accessed on 20 July 2020).

35. WRAP. Courtauld Commitment 2025: Annual review 2017-2018; WRAP: Banbury, UK, 2019. Available online: https://www.wrap.org.uk/sites/files/wrap/Courtauld_2025_Annual_Review_2017_18.pdf (accessed on 20 July 2020).

36. Barr, S.; Gilg, A.W.; Ford, N.J. Differences Between Household Waste Reduction, Reuse and Recycling Behaviour: A Study of Reported Behaviours, Intentions and Explanatory Variables. Environ. Waste Manag. 2001, 4, 69-82.

37. Lober, D.J. Municipal solid waste policy and public participation in household source reduction. Waste Manag. Res. 1996, 14, 125-143. [CrossRef]

38. HLPE. Food Losses and Waste in the Context of Sustainable Food Systems, A Report by the High Level Panel of Experts on Food Security and Nutrition of the Committee on World Food Security; FAO: Rome, Italy, 2014.

39. Monier, V.; Shailendra, M.; Escalon, V.; O'Connor, C.; Gibon, T.; Anderson, G.; Hortense, M.; Reisinger, H. Preparatory Study on Food Waste across EU 27, European Commission (DG ENV) Directorate C-Industry; Final Report; EU: Paris, France, 2010; ISBN 978-92-79-22138-5.

40. Joshi, P.; Visvanathan, C. Sustainable management practices of food waste in Asia: Technological and policy drivers. J. Environ. Manag. 2019, 247, 538-550. [CrossRef]

41. Communication from the Commission to the European Parliament, the Council, the European Economic and Social Committee and the Committee of the Regions. In Closing the Loop-An EU Action Plan for the Circular Economy; European Commission; COM; EU: Brussels, Belgium, 2015. Available online: https://eur-lex.europa. eu/resource.html?uri=cellar:8a8ef5e8-99a0-11e5-b3b7-01aa75ed71a1.0012.02/DOC_1\&format=PDF (accessed on 20 July 2020).

42. Onogawa, K.; Gamaralalage, P.J.; Liu, C. Paradigm Shift from Incineration to Resource Management, and Town Development; UNEP: Osaka, Japan, 2018. Available online: https://wedocs.unep.org/bitstream/handle/20.500. 11822/30994/PSIR.pdf?sequence=1\&isAllowed =y (accessed on 20 July 2020).

43. Li, Y.; Jin, Y.; Li, J.; Chen, Y.; Gong, Y.; Li, Y.; Zhang, J. Current Situation and Development of Kitchen Waste Treatment in China. Procedia Environ. Sci. 2016, 31, 40-49. [CrossRef]

44. Secondi, L.; Principato, L.; Laureti, T. Household food waste behaviour in EU-27 countries: A multilevel analysis. Food Policy 2015, 56, 25-40. [CrossRef]

45. Wansink, B.; van Ittersum, K. Portion size me: Plate-size induced consumption norms and win-win solutions for reducing food intake and waste. J. Exp. Psychol. Appl. 2013, 19, 320-332. [CrossRef] [PubMed]

46. Reynolds, C.; Goucher, L.; Quested, T.; Bromley, S.; Gillick, S.; Wells, V.K.; Evans, D.; Koh, L.; Kanyama, A.C.; Katzeff, C. Review: Consumption-stage food waste reduction interventions-What works and how to design better interventions. Food Policy 2019, 83, 7-27. [CrossRef]

47. Lanfranchi, M.; Calabrò, G.; De Pascale, A.; Fazio, A.; Giannetto, C. Household food waste and eating behavior: Empirical survey. Br. Food J. 2016, 118, 3059-3072. [CrossRef]

48. Poyatos-Racionero, E.; Ros-Lis, J.V.; Vivancos, J.L.; Martínez-Máñez, R. Recent advances on intelligent packaging as tools to reduce food waste. J. Clean. Prod. 2018, 172, 3398-3409. [CrossRef]

49. Schmidt, K.; Matthies, E. Resources, Conservation \& Recycling Where to start fi ghting the food waste problem? Identifying most promising entry points for intervention programs to reduce household food waste and overconsumption of food. Resour. Conserv. Recycl. 2018, 139, 1-14.

50. Schäpke, N.; Rauschmayer, F. Going beyond efficiency: Including altruistic motives in behavioral models for sustainability transitions to address sufficiency. Sustain. Sci. Pract. Policy 2014, 10, 29-44. [CrossRef]

(C) 2020 by the authors. Licensee MDPI, Basel, Switzerland. This article is an open access article distributed under the terms and conditions of the Creative Commons Attribution (CC BY) license (http://creativecommons.org/licenses/by/4.0/). 